\title{
Some Relations between Chemical Structure and Antifungal Effects of Griseofulvin Analogues
}

\author{
By R. CROSSE, R. McWILLIAM AND A. RHODES \\ Glaxo Research Ltd., Sefton Park, Stoke Poges, Buckinghamshire
}

\section{SUMMARY}

Inhibitory effects of more than 300 analogues of griseofulvin against six dermatophytic fungi and eight plant pathogenic fungi were determined in an investigation of relations between chemical structure and biological activity. The influence of chemical structure on physical properties of the analogues appeared dominant, but optimum requirements for in vitro performance were somewhat different from those required in vivo for effective control of plant pathogenic or dermatophytic fungi.

\section{INTRODUCTION}

Griseofulvin is firmly established in many countries as an oral antibiotic for treatment of fungal diseases in medical (Barnett, 1960; Williams, 1960; Sternberg, 1960 ) and in veterinary practice (Uvarov, 1961). The status of griseofulvin in crop protection was reviewed by Rhodes (1962) who concluded that a satisfactory solution to the economics of its utilization might lead to establishment of griseofulvin as a specific plant protectant against the numerous flower-blights and spurblights induced by Sclerotinia species. The relationship between in vitro action against Botrytis allii and systemic antifungal action against Alternaria solani following upon root absorption by tomato plants was examined for griseofulvin and eighteen related compounds by Crowdy, Grove \& McCloskey (1959). They found, in a homologous series of $2^{\prime}$-alkyloxy-analogues of griseofulvin, that in vitro activity increased to a maximum in the $2^{\prime}-n$-propoxy and $2^{\prime}-n$-butoxy analogues, but that further ascent of this homologous series resulted in greatly diminished activity. Systemic antifungal properties were observed in the $2^{\prime}$-ethoxy analogue of griseofulvin but higher members of the series were inactive. Rhodes (1962) questioned the need, implicitin this test, for translocation between so distant tissues; application of analogues to the roots takes little account of the potential benefits that might be gained from local systemic action conferred by ability to penetrate cuticle and to move for relatively short distances through leaf tissues.

Following successful clinical use of griseofulvin, a more extensive series of griseofulvin analogues, prepared for an investigation of relations between structure and biological activity, was described (Arkley, Attenburrow, Gregory \& Walker, 1963; Gregory, Holton, Robinson \& Walker, 1962; Walker, Warburton \& Webb, 1962; Stephenson, Walker, Warburton \& Webb, 1962; Page \& Staniforth, 1962; Arkley, Gregory \& Walker, 1963; Goodall, Gregory \& Walker, 1963; Page \& Staniforth, 1963). We now report some biological results with these compounds against six dermatophytic and eight plant pathogenic fungi in vitro together with observations on antifungal action following upon foliage application of selected 
analogues in vivo against Botrytis cinerea on tomatoes, Erysiphe graminis on barley seedlings, $\boldsymbol{E}$. cichoracearum on cucumber seedlings, Oidium chrysanthemi on chrysanthemums and Venturia inaequalis on apple root stocks.

\section{METHODS}

\section{Laboratory tests}

(i) Test for 'curling' of hyphae. All analogues were compared with griseofulvin in the Botrytis allii test (Brian, Curtis \& Hemming, 1946) for 'curling' and 'stunting' of hyphae, and some of the more active substances were also tested in a similar manner against $B$. cinerea.

(ii) Test for inhibition of radial growth. Serial dilutions of the analogues in modified Sabouraud's maltose agar (4\% maltose; $1 \%$ 'Oxoid' peptone; $2.4 \%$ 'Oxoid' malt extract; $2 \%$ agar adjusted to $\mathrm{pH} 7 \cdot 0$; sterilized at $120^{\circ}$ for $20 \mathrm{~min}$.) were compared against griseofulvin for inhibition of radial growth of dermatophytic and plant pathogenic fungi by adaptation of a bio-assay for griseofulvin described by Grutter, Gaughran, Swartz \& Kamp (1959).

The test micro-organisms were: dermatophytic fungi, Trichophyton rubrum (Castellani) Ota; T. interdigitale Priestley; T. mentagrophytes (Robin) Blanchard; T. persicolor Sabouraud; Microsporum canis Bodin; Epidermophyton floccosum (Herz), Langeron \& Milochevitch; plant pathogenic fungi, Alternaria tenuis Lees ex Corda; Aspergillus niger Van Tiegh.; Botrytis cinerea Fr.; Cercospora melonis Cooke; Fusarium nivale Auct.; Glomerella cingulata (Stonem), Spauld.; Sclerotinia fructigena Aderk \& Ruhl.; Thielaviopsis basicola (Berk \& Br), Ferraris.

A measured part of a solution of the analogue $(1 \mathrm{mg} . / \mathrm{ml}$.) in acetone + ethanol $(1+1$ by vol.) was diluted into sterile distilled water to give twice the highest concentration of analogue required in the final agar test plates; dilution of this solution with distilled water afforded a range of twofold serial dilutions. Double strength agar medium $(6 \mathrm{ml}$.) was mixed with an equal volume of each serial dilution and the completed agar test-media, containing analogue 20 to $0 \cdot 31 \mu \mathrm{g}$. $/ \mathrm{ml}$., were poured into Petri dishes and allowed to set. The three controls consisted of agar containing no solvent and the two highest concentrations of solvent.

Inocula of the test fungi were prepared from cultures on slopes of modified Sabouraud maltose agar medium. The confluent surface growth in each culture was flooded with sterile distilled water and scraped with a wire loop to give a suspension that was homogenized before mixing with molten $\left(47^{\circ}\right)$ agar medium (modified Sabouraud maltose) in Petri dishes and cooled to solidify. Petri dish cultures of Aspergillus niger were stored overnight at $4^{\circ}$, but the rest were incubated at $26^{\circ}$ for 16,24 or $48 \mathrm{hr}$ (depending upon the rate of growth of individual organisms) before use. Plugs (7 mm. diameter) cut with a cork-borer from each fungal culture were transferred to the surfaces of the agar test media containing serial dilutions of the analogue to be evaluated. Six dermatophytes, five slow-growing plant pathogens or three fast-growing plant pathogens were distributed in this manner on the surface of each agar test medium and incubated at $\mathbf{2 6}^{\circ}$.

The inhibitory effect of any given concentration of analogue was determined by measuring the radial growth of each test fungus from the seeded plugs at the end of incubation for 3 days (plant pathogens) or 6 days (dermatophytes). When the 
analogue concentration prevented radial growth, the extent of inhibition was graded on a scale of 0-3 according to the density of growth within the agar plug inoculum. In each test, a corresponding series of agar media containing serial dilutions of griseofulvin instead of analogue was prepared and inoculated with the same test fungi to compare directly the inhibitory effects of analogue and griseofulvin on fungal growth.

(iii) Test for growth inhibition in static liquid cultures. The analogues were compared with griseofulvin by conventional tube dilution assay against liquid cultures of Candida albicans (medium: $4 \%$ glucose, 1\% 'Oxoid' peptone, 2.1\% 'Oxoid' malt extract; adjusted to $\mathrm{pH} 7 \cdot 0$ and sterilized at $120^{\circ}$ for $20 \mathrm{~min}$.) and Bacillus subtilis (medium: $0.5 \% \mathrm{NaCl}, 1 \%$ 'Evans' peptone, $1 \%$ 'Lab. Lemco'; adjusted to $\mathrm{pH} 8.4$ and boiled for $30 \mathrm{~min}$. before filtration through kieselguhr, re-adjusted to $\mathrm{pH} \mathrm{7.2}$ with $\mathrm{HCl}$ and sterilized at $120^{\circ}$ for $20 \mathrm{~min}$.). Complete inhibition of growth in this test may be identified by absence of a white sediment after incubation of $C$. albicans for $24 \mathrm{hr}$ at $26^{\circ}$ or by absence of a surface pellicle of $B$. subtilis after incubation for $24 \mathrm{hr}$ at $37^{\circ}$.

\section{Greenhouse tests}

(i) Botrytis cinerea on tomatoes. The greenhouse test described by Crosse, McWilliam, Rhodes \& Dunn (1960) for assessment of fungicidal activity against Phytophthora infestans on tomatoes was adapted to evaluation of griseofulvin analogues against Botrytis cinerea. Stonor's M.P. tomato plants, grown for about 4 weeks under fluorescent lights ( $80 \mathrm{~W}$. spaced at 4 in. centres), were ready for use when the sixth compound leaf was clearly visible. In each experiment, forty-nine plants were arranged in a $7 \times 7$ Latin square. Suspensions or solutions of the analogues were prepared by addition of 'Sorbester PQ 12' (mixed sorbitan monolaurate and polyoxyethylene condensate) to a solution of the analogue in methylethylketone and then dilution with water gave the required concentration of analogue in $0.5 \%$ solvent $+0.08 \%$ of wetting-out agent. Treatments were applied by means of a B.E.N. model R.F. 4 spray-gun (B.E.N. Patents Ltd. High Wycombe, Bucks.), operated at a constant pressure of $10 \mathrm{lb}$./sq.in., to both surfaces of the second, third and fourth leaves above the cotyledons, so as to wet the leaflets completely but without run-off.

Inoculum was prepared by suspending in Weindling's medium the conidia from a freely-sporulating culture of Botrytis cinerea (isolated from Vitis vinifera and maintained on modified Sabouraud maltose agar medium) and diluting with Weindling medium to a concentration of 100,000 spores $/ \mathrm{ml}$. This suspension of spores was applied with a B.E.N. model 5 no. 1 spray-gun, operated at a pressure of $10 \mathrm{lb}$./sq.in., to the ventral surfaces only of the three treated leaves on each plant, with use of no more suspension than was necessary to give a uniform cover of small but discrete droplets of fluid. The inoculated plants were incubated in a saturated atmosphere, provided by a polythene humidity chamber cooled by an external spray of cold water, until discrete lesions developed after $72 \mathrm{hr}$. The aggregate of lesions on the three inoculated leaves of each plant was taken as a measure of the incidence of disease. The mean number of lesions on seven treated plants compared with the mean obtained from corresponding leaves of control plants gave an estimate of the antifungal protection afforded by treatment.

Effectiveness of treatments against the aggressive form of the disease was 
determined by extension of the incubation period to 7 days and then by grading of leaves according to percentage of leaf area destroyed; comparison of mean grades from control and treated plants gave an estimate of protection afforded by treatment.

Local systemic action of the analogues was assessed from the antifungal protection obtained when treatment sprays were confined to the dorsal surfaces only of the leaves, but the pathogenic inoculum was applied to the ventral surfaces in the usual manner.

(ii) Erysiphe graminis on barley seedlings. Barley seedlings (variety 'Proctor') were grown, 10 to 15 seedlings in each 3 in. clay pot, to a height of about 5 in. and then decreased in number to leave ten uniform seedlings in each pot. Growing conditions were similar to those already described for raising tomato plants. Each treatment was sprayed from a B.E.N. (model R.F. 4) spray gun, operating at a constant pressure of $10 \mathrm{lb}$./sq.in., to the foliage of seedlings in three replicate pots and allowed to dry before the pots were transferred to an enclosed section (10 ft. $\times$ $22 \mathrm{ft}$.) of another greenhouse which served as an inoculation chamber. This contained two square tables spaced about $4 \mathrm{ft}$. apart; one supported the inoculum provided by many boxes of strongly growing barley plants heavily infected with $E$. graminis; on the other, experimental plants were randomly arranged with their foliage orientated in a horizontal position so as to expose a large leaf area to spore deposition.

Inoculation was effected by blowing air from a 'Microsol' mist generator for about 20 sec. across the table of infected plants in the opposite direction from the experimental seedlings, so that a spore cloud moved up the side of the inoculation chamber into the roof. After a further short blast of air, now directed towards the roof, the evenly dispersed spores were allowed to settle in still air for a period of $18 \mathrm{hr}$. The potted seedlings were then removed to a third greenhouse, free from cereal mildew, and the discrete lesions which appeared 7 days later on the primary leaves were counted to determine the number of lesions on the ten seedlings in each pot. The number of lesions of three treated pots was compared with the corresponding mean from untreated seedlings to give an estimate of the antifungal protection achieved by treatment.

(iii) Erysiphe cichoracearum on cucumber. Cucumber seedlings (variety 'Improved Telegraph') grown under conditions similar to those used for the tomato and barley plants were ready for test when the first true leaf was about half expanded. Plants were arranged in a $6 \times 6$ Latin square and the treatments were applied as foliage sprays at 7-day intervals. Twenty cucumber plants, heavily infected with $\boldsymbol{E}$. cichoracearum, were evenly arranged around the Latin square so as to provide continuous spore inoculum for the test plants. The antifungal effects of treatment were estimated by comparison of the mean number of discrete mildew colonies per plant in each treatment with the corresponding mean obtained from the control plants which had been sprayed with $0.5 \%$ methylethylketone $+0.08 \%$ 'Sorbester PQ12' only.

(iv) Oidium chrysanthemi on chrysanthemums. Pot-grown chrysanthemums (varieties 'Sterling' and 'Mayford Perfection'), lightly infected with mildew, were available for test under glasshouse conditions when about $3 \mathrm{ft}$. high with crown buds just visible. Each treatment was given to three plants of each variety 
selected at random, and the treatments were applied as foljage sprays at fortnightly intervals from the middle of October onwards. The course of the disease was followed by estimations made at intervals from the middle of November until early January. Each leaf was scored according to the area covered by the fungus, and the effect of treatment was estimated by comparing the mean score of the treated plants with the corresponding mean of untreated control plants.

(v) Venturia inaequalis on apples. Griseofulvin analogues were tested against $V$. inaequalis on apple root stocks (Malling Merton 106) grown under glass in 10 in. clay pots. Daylight was supplemented as necessary, so as to provide illumination for $16 \mathrm{hr}$ each day throughout the year. The rootstocks were pruned hard to encourage four or five buds to break and develop into shoots about 6 in. in length.

Treatments were sprayed at a constant pressure of $10 \mathrm{lb}$./sq.in. from a B.E.N. spray gun (model R.F. 4) on the dorsal surfaces of the five youngest leaves of each shoot so as to wet the surfaces completely but without run-off: there were four replicates.

An inoculum containing 300,000 conidia $/ \mathrm{ml}$. was prepared by pipetting $10 \mathrm{ml}$. sterile distilled water into 14-day filter-paper culture tubes (Kirkham, 1956), shaking vigorously, filtering the resultant suspensions through butter muslin to remove fragments of mycelium and finally diluting as necessary. This spore suspension was sprayed from a B.E.N. spray gun (Model S no. 1), operating at a constant pressure of $10 \mathrm{lb}$./sq.in., onto the leaves, so as to give a uniform cover of small, discrete droplets.

Immediately after inoculation, each rootstock was enveloped in a saturated atmosphere provided by a large polythene bag that was thoroughly moistened on the inside. Each bag was tied firmly around the rim of the pot, and the polythene was held clear of the foliage by four internal supporting canes. The foliage was maintained wet for $48 \mathrm{hr}$ by keeping the plants at $15-20^{\circ}$ in subdued light. At the end of this infection period, the polythene bags were removed, and the plants returned to the greenhouse. Lesions appeared after 10-14 days depending on the temperature.

The decrease in disease due to treatment was estimated by comparing the mean lesion count/leaf for each treatment against the corresponding value for control plants. In some experiments the infection of controls was so severe that the lesions coalesced, making it necessary to grade leaves according to the percentage area of damaged lamina: mean grade/leaf was then substituted for mean lesion count/leaf in estimating the effects of treatments.

\section{RESULTS}

Analogues of griseofulvin which proved to be more active than griseofulvin against one or more of the test fungi in vitro are listed in Table $\mathrm{I} a, \mathrm{I} b$ and $\mathrm{I} c$ : none was active against the test bacterium or yeast. It is clear that the antifungal spectrum of griseofulvin can be profoundly altered by changes in chemical structure.

Increase in antifungal action over that of griseofulvin was usually specific to one or a few species. The broadest spectrum of enhanced activity was shown by the 2 '-ethoxy-3'-benzyl analogue of griseofulvin (R 10/141), which had greater activity than griseofulvin against all test fungi except Thielaviopsis basicola. Increased or decreased length of the 2 '-alkyloxy side-chain in this homologous series first made 


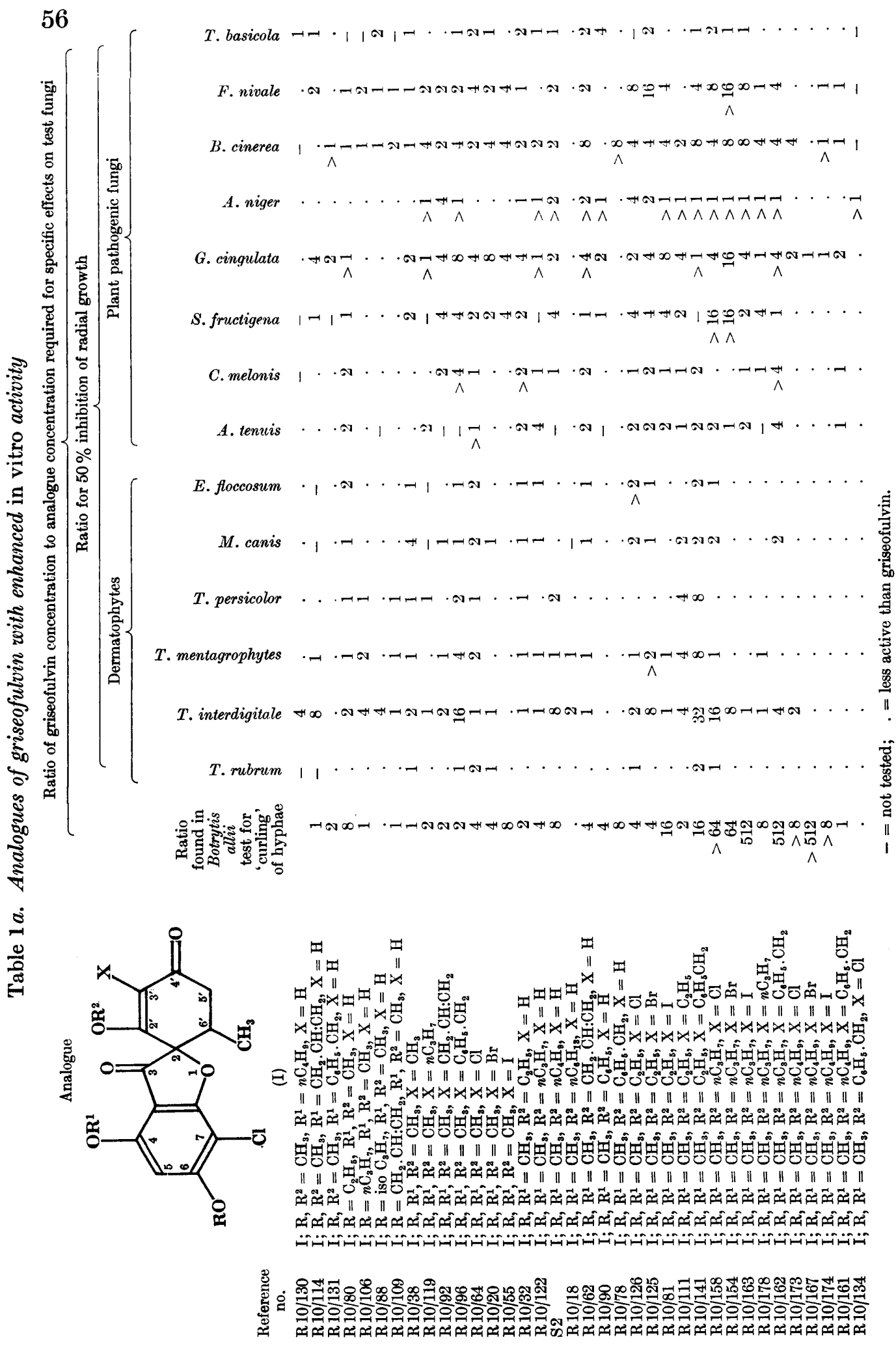




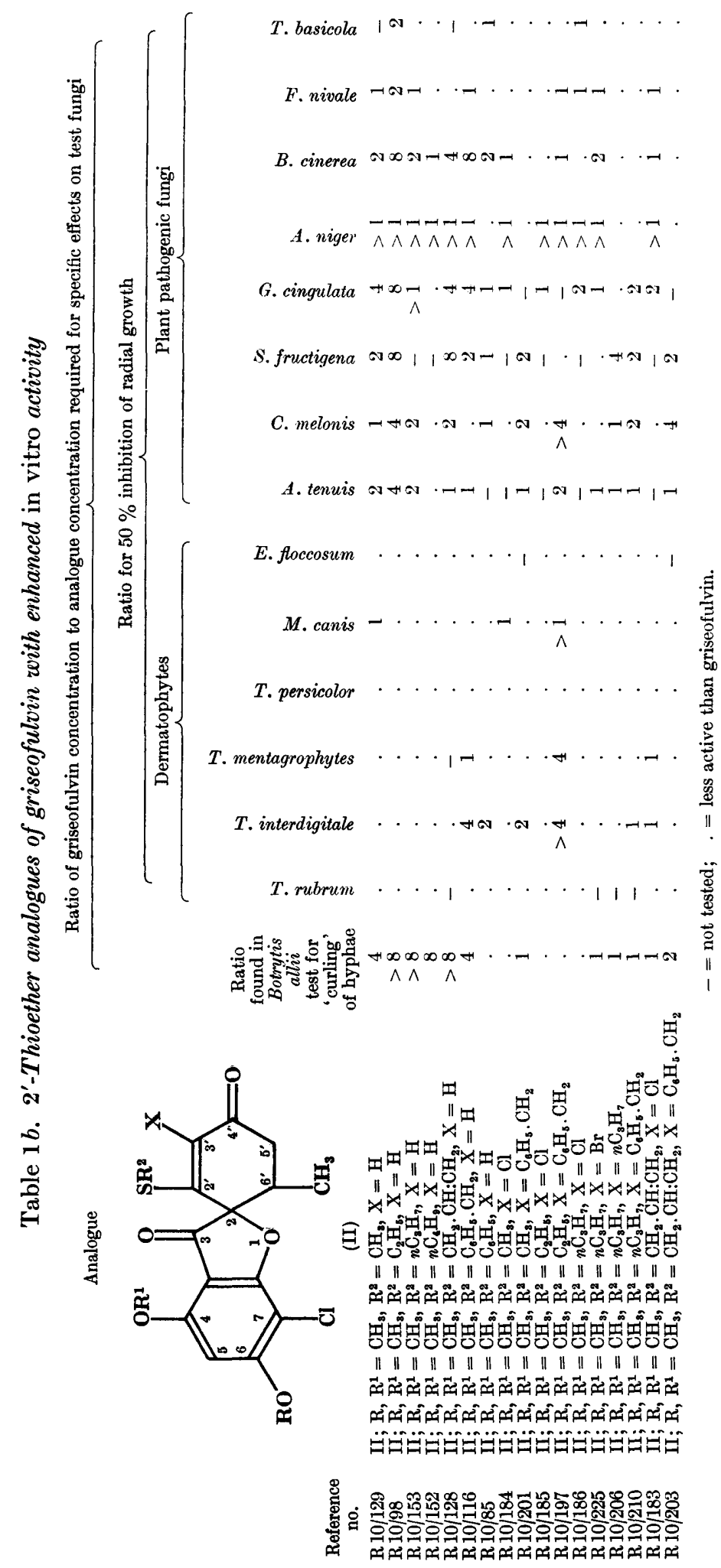




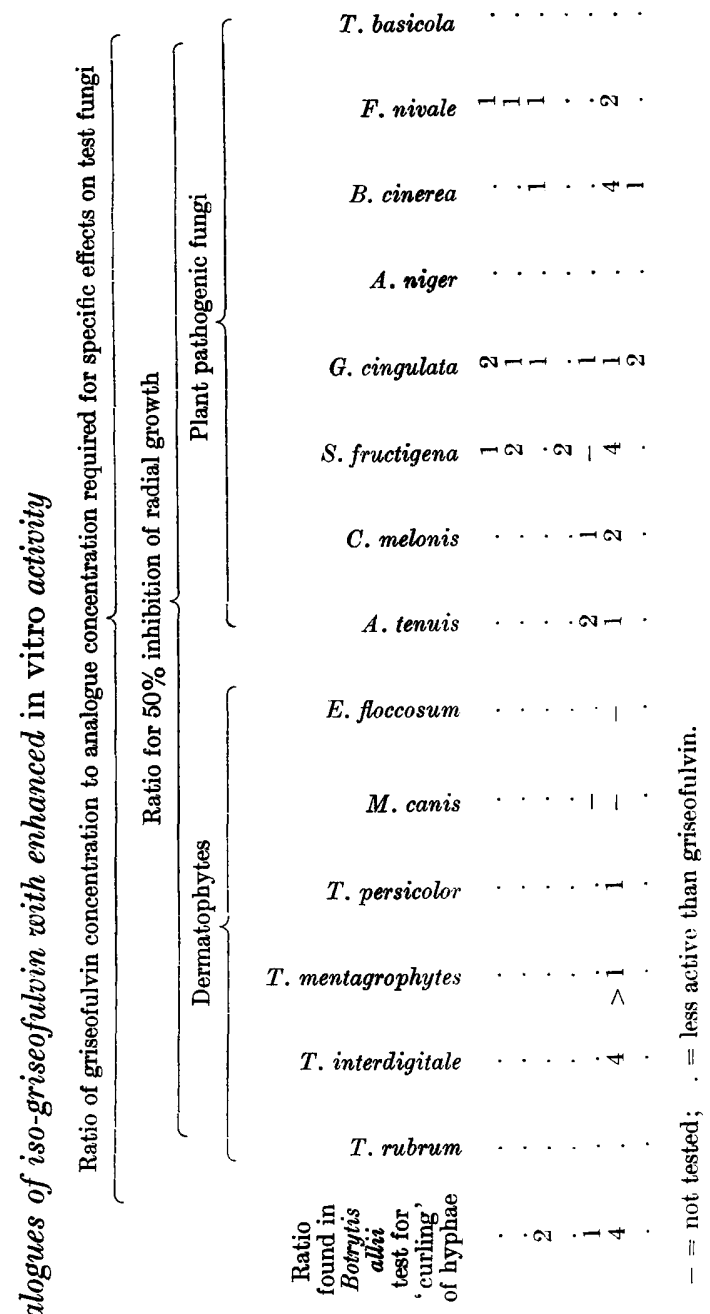

这

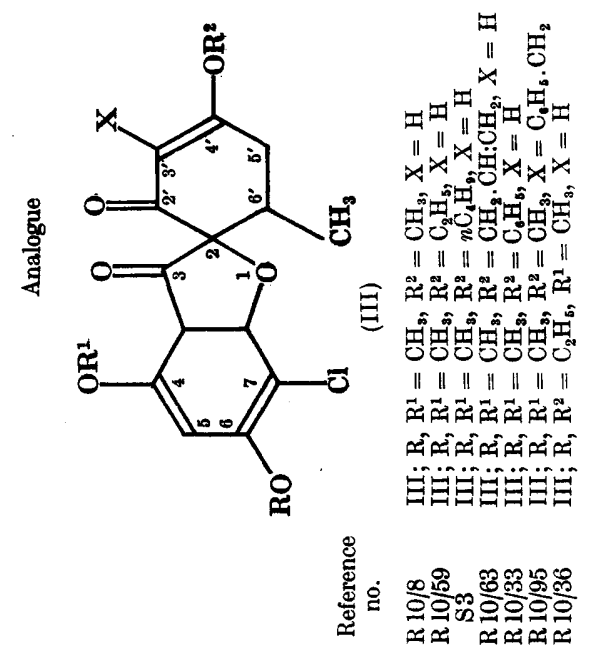


more specific the increase in antifungal action over that of griseofulvin, e.g. the $2^{\prime}$-propoxy-3'-benzyl (R 10/162) and $3^{\prime}$-benzyl (R 10/96) analogues of griseofulvin, and then diminished the antifungal activity against most of the test fungi, e.g. $2^{\prime}$-n-butoxy-3'-benzyl analogue of griseofulvin (R 10/161). A similar but not quite so wide range of enhanced antifungal activity was also observed in the $2^{\prime}$-alkyloxy3'-chloro-, 2'-alkyloxy-3'-bromo- and 2'-alkyloxy-3'-iodo-homologous series of griseofulvin analogues, but the peak activity in each of these series was shown by the 2 '-propoxy-3'-halogen analogues of griseofulvin.

Taking the analogues as a whole, it was generally observed that increased activity against the plant pathogens predominated over enhanced action against dermatophytes. Replacements in the $\mathbf{2}^{\prime}$-position or substitution in the $\mathbf{3}^{\prime}$-position produced the greatest improvement in antifungal action in vitro, particularly against Botrytis cinerea and Sclerotinia fructigena. Replacement of the $\mathbf{2}^{\prime}$-methoxy group of griseofulvin by homologous alkyloxy groups had the greatest effect, maximum activity being found in the $2^{\prime}$-propoxy analogue of griseofulvin (R 10/122) with the $2^{\prime}$-n-butoxy (S2) and $2^{\prime}$-ethoxy (R 10/32) analogues of griseofulvin next in order of activity. Replacement by allyloxy ( $R$ 10/62) or benzyloxy ( $R$ 10/78) at the $2^{\prime}$-position in griseofulvin increased activity against $B$. cinerea in vitro, but had no effect (R 10/62) or reduced (R 10/78) activity against $S$. fructigena. Halogen, benzyl or certain alkyl groups substituted at the $\mathbf{3}^{\prime}$-position of griseofulvin also resulted in enhanced activity in vitro against $B$. cinerea and $S$. fructigena. Enhancement of activity by $3^{\prime}$-halogen substitution increased in the order $\mathrm{Cl}(\mathrm{R} \mathrm{10/64})$, $\mathrm{Br}(\mathrm{R} \mathbf{1 0} / 20)$ to I (R 10/55). Association of the more active substituent groups at the $\mathbf{3}^{\prime}$-position with the more active replacement groups at the $\mathbf{2}^{\prime}$-position showed a potentiated response against $B$. cinerea and $S$. fructigena in several analogues. The greatest improvement resulted from 2 '-propoxy replacement along with $3^{\prime}$ substitution of $\mathrm{I}(\mathrm{R} \mathrm{10/163)}) \mathrm{Br}(\mathrm{R}$ 10/154) or $\mathrm{Cl}$ (R 10/158). Similar but less marked effects were found when $2^{\prime}$-ethoxy replacement was associated with halogen substitution at the $\mathbf{3}^{\prime}$-position of griseofulvin.

Some of these $2^{\prime}, \mathbf{3}^{\prime}$-analogues of griseofulvin showed phenomenal improvement in activity in the 'hyphal curling' test on Botrytis allii: the 2 '-butoxy-3'-bromo (R 10/167), 2'-propoxy-3'-iodo (R 10/163) and 2'-propoxy-3'-benzyl (R 10/162) analogues of griseofulvin were more than $\mathbf{5 0 0}$ times as active as griseofulvin itself. This exceptionally high activity was also specific, as it was approached neither in the Petri dish tests nor when $\boldsymbol{B}$. cinerea was substituted for $\boldsymbol{B}$. allii in the 'hyphalcurling' test.

Substantially increased activity against most of the plant pathogenic fungi was observed also in the $2^{\prime}$-alkyl-thioether analogues of griseofulvin (Table $1 b$ ), but in this series there was no potentiated response when any of the $2^{\prime}$-replacements were associated with an activating substituent at the $\mathbf{3}^{\prime}$-position. The $2^{\prime}$-ethyl-thioether analogue of griseofulvin ( $R$ 10/98) must probably be considered the most active among analogues of this type, with the corresponding 2 '-allyl-(R 10/128) and $2^{\prime}$-benzyl-(R 10/116) thioethers next in order of activity and broadness of antifungal spectrum. It is notable that in this series the $2^{\prime}$-n-butoxy-thioether (R 10/152) showed improvement only against Botrytis allii and Aspergillus niger.

Some of the analogues that showed most promise against the plant pathogenic fungi in vitro were also tested for inhibiting radial growth of a plant pathogenic 
strain of Stereum purpureum. The 2'-propoxy-3'-propyl analogue of griseofulvin (R 10/178) was found to be the most active (minimum inhibitory concentration $<0.3 \mu \mathrm{g}$. $/ \mathrm{ml}$.) of those tested, with the $2^{\prime}$-ethoxy-3'-benzyl analogue of griseofulvin (R 10/141) and the $3^{\prime}$-iodo analogue of griseofulvin (R 10/55) effective at $0.6 \mu \mathrm{g} . /$ $\mathrm{ml}$ : griseofulvin required $\mathbf{1 0 - 2 0} \mu \mathrm{g}$./ml. for complete inhibition.

Only a few analogues of isogriseofulvin (R 10/8) showed any marked improvement over griseofulvin in vitro. The $3^{\prime}$-benzyl analogue of isogriseofulvin ( $R$ 10/95) exhibited the broadest spectrum of improved antifungal action, but the improvement shown by most other analogues of this type was fairly specific to Sclerotinia fructigena and Glomerella cingulata (Table 1c). Isogriseofulvin itself was less active

Table 2. Average performances of some griseofulvin analogues in greenhouse foliage protection tests against Botrytis cinerea on tomato

\begin{tabular}{|c|c|c|c|c|}
\hline \multirow[b]{2}{*}{ Ref. no. } & \multirow[b]{2}{*}{ Analogue } & \multicolumn{3}{|c|}{$\begin{array}{l}\text { Approximate activity } \\
\text { relative to griseofulvin }\end{array}$} \\
\hline & & $\begin{array}{l}\text { Less } \\
\text { active }\end{array}$ & $\begin{array}{c}\text { Equal } \\
\text { activity }\end{array}$ & $\begin{array}{l}\text { More } \\
\text { active }\end{array}$ \\
\hline $\begin{array}{l}\text { R } 10 / 96 \\
R 10 / 92 \\
R 10 / 55\end{array}$ & $\begin{array}{l}\mathbf{I} ; \mathbf{R}, \mathbf{R}^{1}, \mathbf{R}^{2}=\mathbf{C H}_{3}, \mathbf{X}=\mathbf{C}_{6} \mathbf{H}_{5} \\
\mathbf{I} ; \mathbf{R}, \mathbf{R}^{\mathbf{1}}, \mathbf{R}^{2}=\mathbf{C H}_{3}, \mathbf{X}=\mathbf{C H}_{\mathbf{2}} . \mathbf{C H}: \mathbf{C H}_{2} \\
\mathbf{I} ; \mathbf{R}, \mathbf{R}^{1}, \mathbf{R}^{2}=\mathbf{C H}_{3}, \mathbf{X}=\mathbf{I}\end{array}$ & $\begin{array}{l}* \\
* \\
.\end{array}$ & $\dot{\cdot}$ & $\dot{.}$ \\
\hline $\begin{array}{l}\text { R 10/32 } \\
\text { R 10/122 } \\
\text { S2 } \\
\text { R10/18 } \\
\text { R 10/62 }\end{array}$ & $\begin{array}{l}\mathbf{I} ; \mathbf{R}, \mathbf{R}^{1}=\mathbf{C H}_{3}, \mathbf{R}^{2}=\mathbf{C}_{2} \mathbf{H}_{5}, \mathbf{X}=\mathbf{H} \\
\mathbf{I} ; \mathbf{R}, \mathbf{R}^{1}=\mathbf{C H}_{3}, \mathbf{R}^{2}=n \mathbf{C}_{3} \mathbf{H}_{7}, \mathbf{X}=\mathbf{H} \\
\mathbf{I} ; \mathbf{R}, \mathbf{R}^{1}=\mathbf{C H}_{3}, \mathbf{R}^{2}=n \mathbf{C}_{4} \mathbf{H}_{9}, \mathbf{X}=\mathbf{H} \\
\mathbf{I} ; \mathbf{R}, \mathbf{R}^{1}=\mathbf{C H}_{3}, \mathbf{R}^{2}=n \mathbf{C}_{6} \mathbf{H}_{13}, \mathbf{X}=\mathbf{H} \\
\mathbf{I} ; \mathbf{R}, \mathbf{R}^{1}=\mathbf{C H}_{3}, \mathbf{R}^{2}=\mathbf{C H}_{2} . \mathbf{C H}: \mathbf{C H}_{2}, \mathbf{X}=\mathbf{H}\end{array}$ & $\begin{array}{l}\dot{.} \\
\dot{.} \\
\dot{ }\end{array}$ & $\begin{array}{l}* \\
\dot{.} \\
\dot{.} \\
\text {. }\end{array}$ & $\begin{array}{l}\dot{*} \\
* \\
* \\
*\end{array}$ \\
\hline $\begin{array}{l}\text { R } 10 / 126 \\
\text { R } 10 / 125 \\
\text { R } 10 / 81 \\
\text { R } 10 / 141 \\
\text { R } 10 / 158 \\
\text { R } 10 / 154 \\
\text { R } 10 / 163 \\
\text { R } 10 / 178 \\
R 10 / 162 \\
\text { R } 10 / 173 \\
\text { R } 10 / 174\end{array}$ & $\begin{array}{l}\mathbf{I} ; \mathbf{R}, \mathbf{R}^{1}=\mathbf{C H}_{3}, \mathbf{R}^{2}=\mathbf{C}_{2} \mathbf{H}_{5}, \mathbf{X}=\mathbf{C l} \\
\mathbf{I} ; \mathbf{R}, \mathbf{R}^{1}=\mathbf{C H}_{3}, \mathbf{R}^{2}=\mathbf{C}_{2} \mathbf{H}_{5}, \mathbf{X}=\mathbf{B r} \\
\mathbf{I} ; \mathbf{R}, \mathbf{R}^{1}=\mathbf{C H}_{3}, \mathbf{R}^{2}=\mathbf{C}_{2} \mathbf{H}_{5}, \mathbf{X}=\mathbf{I} \\
\mathbf{I} ; \mathbf{R}, \mathbf{R}^{1}=\mathbf{C H}_{3}, \mathbf{R}^{2}=\mathbf{C}_{2} \mathbf{H}_{5}, \mathbf{X}=\mathbf{C}_{6} \mathbf{H}_{5} \\
\mathbf{I} ; \mathbf{R}, \mathbf{R}^{1}=\mathbf{C H}_{3}, \mathbf{R}^{2}=n \mathbf{C}_{3} \mathbf{H}_{7}, \mathbf{X}=\mathbf{C l} \\
\mathbf{I} ; \mathbf{R}, \mathbf{R}^{1}=\mathbf{C H}_{3}, \mathbf{R}^{2}=n \mathbf{C}_{3} \mathbf{H}_{7}, \mathbf{X}=\mathbf{B r} \\
\mathbf{I} ; \mathbf{R}, \mathbf{R}^{1}=\mathbf{C H}_{3}, \mathbf{R}^{2}=n \mathbf{C}_{3} \mathbf{H}_{7}, \mathbf{X}=\mathbf{I} \\
\mathbf{I} ; \mathbf{R}, \mathbf{R}^{1}=\mathbf{C H}_{3}, \mathbf{R}^{2}=n \mathbf{C}_{3} \mathbf{H}_{7}, \mathbf{X}=n \mathbf{C}_{3} \mathbf{H}_{7} \\
\mathbf{I} ; \mathbf{R}, \mathbf{R}^{1}=\mathbf{C H}_{3}, \mathbf{R}^{2}=n \mathbf{C}_{3} \mathbf{H}_{7}, \mathbf{X}=\mathbf{C}_{6} \mathbf{H}_{5} \\
\mathbf{I} ; \mathbf{R}, \mathbf{R}^{1}=\mathbf{C H}_{3}, \mathbf{R}^{2}=n \mathbf{C}_{4} \mathbf{H}_{9}, \mathbf{X}=\mathbf{C I} \\
\mathbf{I} ; \mathbf{R}, \mathbf{R}^{1}=\mathbf{C H}_{3}, \mathbf{R}^{2}=n \mathbf{C}_{4} \mathbf{H}_{9}, \mathbf{X}=\mathbf{I}\end{array}$ & $\begin{array}{l}\dot{.} \\
\dot{.} \\
\dot{.} \\
\dot{.} \\
\dot{.} \\
\dot{.} \\
\dot{.} \\
\dot{.}\end{array}$ & $\begin{array}{l}* \\
\dot{.} \\
\dot{.} \\
\dot{.} \\
\dot{.} \\
\dot{.} \\
\dot{.} \\
\dot{.} \\
*\end{array}$ & $\begin{array}{l}\dot{*} \\
* \\
* \\
* \\
* \\
* \\
* \\
* \\
* \\
.\end{array}$ \\
\hline R 10/109 & $\mathrm{I} ; \mathbf{R}=\mathrm{CH}_{2}, \mathrm{CH}: \mathrm{CH}_{2}, \mathbf{R}^{1}, \mathbf{R}^{2}=\mathrm{CH}_{3}, \mathbf{X}=\mathbf{H}$ & * & $\cdot$ & . \\
\hline $\begin{array}{l}\text { R } 10 / 129 \\
\text { R } 10 / 98 \\
\text { R } 10 / 153 \\
\text { R } 10 / 128 \\
\text { R } 10 / 116 \\
\text { R } 10 / 85\end{array}$ & 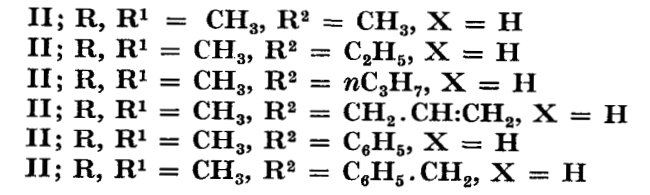 & $\begin{array}{l}* \\
\dot{*} \\
\dot{*} \\
*\end{array}$ & $\begin{array}{l}\dot{\cdot} \\
\dot{\cdot} \\
\dot{.} \\
\dot{.}\end{array}$ & $\begin{array}{l}\dot{*} \\
\dot{*} \\
\dot{.} \\
\dot{0}\end{array}$ \\
\hline $\mathbf{R ~ 1 0 / 9 5}$ & $\mathbf{I I I} ; \mathbf{R}, \mathbf{R}^{1}, \mathbf{R}^{2}=\mathbf{C H}_{3}, \mathbf{X}=\mathbf{C}_{6} \mathbf{H}_{5}$ & . & $\cdot$ & $*$ \\
\hline
\end{tabular}

than griseofulvin against all test fungi except G. cingulata. Neither griseofulvic acid nor any of its analogues was as effective as griseofulvin in any of the tests. Most replacements at other positions in the griseofulvin molecule diminished antifungal activity to below that of griseofulvin, although a few of the 4- or 6-alkyloxy analogues of griseofulvin (Table $1 a$ ) showed an improvement limited to a few species.

Selected analogues more active than griseofulvin against Botrytis cinerea in vitro were tested at $20 \mu \mathrm{g} . / \mathrm{ml}$. concentration for ability to protect foliage of young 
tomato plants against $\boldsymbol{B}$. cinerea in greenhouse tests. Average performances in a considerable number of greenhouse tests are summarized in Table 2. In general, analogues that exhibited enhanced activity in vitro also showed to advantage in the greenhouse tests, but it was noted that the most active of the 2 '-alkyloxy analogues of griseofulvin were relatively better in vivo, whereas the most active of the $2^{\prime}$-alkyloxy-3'-substituted analogues of griseofulvin were relatively worse than had been expected. It was notable that, although the $\mathbf{3}^{\prime}$-benzyl analogue of griseofulvin (R 10/96) and the $3^{\prime}$-benzyl analogue of isogriseofulvin ( $R$ 10/95) showed a similar enhancement of activity in vitro, the former was completely inactive in the greenhouse protection test, but the latter performed much better than might have been expected.

Table 3. Local systemic protection against Botrytis cinerea afforded to ventral leaf surfaces of tomato by griseofulvin analogues applied to dorsal surfaces

\begin{tabular}{|c|c|c|c|c|}
\hline \multirow[b]{2}{*}{ Ref. no. } & \multirow[b]{2}{*}{ Analogue } & \multicolumn{3}{|c|}{$\begin{array}{l}\text { Approximate activity } \\
\text { relative to griseofulvin }\end{array}$} \\
\hline & & $\begin{array}{l}\text { Less } \\
\text { active }\end{array}$ & $\begin{array}{c}\text { Equal } \\
\text { activity }\end{array}$ & $\begin{array}{c}\text { More } \\
\text { active }\end{array}$ \\
\hline R 10/92 & $\mathrm{I} ; \mathbf{R}, \mathbf{R}^{1}, \mathbf{R}^{2}=\mathrm{CH}_{3}, \mathrm{X}=\mathrm{CH}_{2}, \mathrm{CH}: \mathrm{CH}_{2}$ & * & . & . \\
\hline R10/122 & $\mathbf{I} ; \mathbf{R}, \mathbf{R}^{1}=\mathbf{C H}_{3}, \mathbf{R}^{2}=n \mathbf{C}_{3} \mathbf{H}_{7}, \mathbf{X}=\mathbf{H}$ & . & . & * \\
\hline S2 & $\mathrm{I} ; \mathbf{R}, \mathbf{R}^{1}=\mathrm{CH}_{3}, \mathbf{R}^{2}=n \mathrm{C}_{4} \mathbf{H}_{9}, \mathrm{X}=\mathbf{H}$ & . & * & . \\
\hline R 10/81 & $\mathbf{I} ; \mathbf{R}, \mathbf{R}^{1}=\mathbf{C H}_{3}, \mathbf{R}^{2}=\mathbf{C}_{2} \mathbf{H}_{5}, \mathbf{X}=\mathbf{I}$ & . & $*$ & . \\
\hline $\begin{array}{l}\text { R } 10 / 158 \\
\text { R } 10 / 154 \\
\text { R } 10 / 163 \\
\text { R } 10 / 173 \\
\text { R } 10 / 174\end{array}$ & $\begin{array}{l}\mathbf{I} ; \mathbf{R}, \mathbf{R}^{1}=\mathbf{C H}_{3}, \mathbf{R}^{2}=n \mathbf{C}_{3} \mathbf{H}_{7}, \mathbf{X}=\mathbf{C l} \\
\mathbf{I} ; \mathbf{R}, \mathbf{R}^{1}=\mathbf{C H}_{3}, \mathbf{R}^{2}=n \mathbf{C}_{3} \mathbf{H}_{7}, \mathbf{X}=\mathbf{B r} \\
\mathbf{I} ; \mathbf{R}, \mathbf{R}^{1}=\mathbf{C H}_{3}, \mathbf{R}^{2}=n \mathbf{C}_{3} \mathbf{H}_{7}, \mathbf{X}=\mathbf{I} \\
\mathbf{I} ; \mathbf{R}, \mathbf{R}^{1}=\mathbf{C H}_{3}, \mathbf{R}^{2}=n \mathbf{C}_{4} \mathbf{H}_{9}, \mathbf{X}=\mathbf{C l} \\
\mathbf{I} ; \mathbf{R}, \mathbf{R}^{1}=\mathbf{C H}_{3}, \mathbf{R}^{2}=n \mathbf{C}_{4} \mathbf{H}_{9}, \mathbf{X}=\mathbf{I}\end{array}$ & $\begin{array}{l}\dot{.} \\
\dot{*} \\
\dot{.}\end{array}$ & $\begin{array}{l}\dot{\cdot} \\
\dot{\cdot} \\
\dot{\cdot}\end{array}$ & $\begin{array}{l}* \\
* \\
* \\
. \\
.\end{array}$ \\
\hline R 10/129 & II $; \mathbf{R}, \mathbf{R}^{1}=\mathbf{C H}_{3}, \mathbf{R}^{2}=\mathbf{C H}_{3}, \mathbf{X}=\mathbf{H}$ & . & * & $\cdot$ \\
\hline $\mathbf{R ~ 1 0 / 9 8}$ & II $; \mathbf{R}, \mathbf{R}^{1}=\mathbf{C H}_{3}, \mathbf{R}^{2}=\mathbf{C}_{2} \mathbf{H}_{5}, \mathbf{X}=\mathbf{H}$ & . & * & . \\
\hline R10/153 & $\mathrm{II} ; \mathbf{R}, \mathbf{R}^{1}=\mathbf{C H}_{3}, \mathbf{R}^{2}=n \mathbf{C}_{3} \mathbf{H}_{7}, \mathbf{X}=\mathbf{H}$ & * & . & . \\
\hline
\end{tabular}

Similar results were obtained (Table 3) when some of these analogues were tested for local systemic action in experiments that depended upon movement from the dorsal to the ventral leaf surface. In general, the analogues tested were about half as effective in the test for local systemic action as in the normal foliage protection test.

Previous experience had shown that griseofulvin had some activity against apple scab (Venturia inaequalis) in greenhouse protection tests on apple root stocks and that a concentration of $200 \mu \mathrm{g}$./ml. was about equivalent to LD 60. This test seems to put a premium on systemic action, and it was decided to evaluate in this manner some of the analogues that had proved to have good local systemic action. The analogues listed below were found to be much more effective than griseofulvin in these greenhouse tests against apple scab, $200 \mu \mathrm{g} . / \mathrm{ml}$. of each analogue affording more than $90 \%$ protection against the disease: $R$ 10/96-I; $R, R^{1}, R^{2}=C_{3}, X=$ $\mathrm{C}_{6} \mathrm{H}_{5} . \mathrm{CH}_{2} ; \mathrm{R} \mathrm{10/32-I} ; \mathrm{R}, \mathrm{R}^{1}=\mathrm{CH}_{3}, \mathrm{R}^{2}=\mathrm{C}_{2} \mathrm{H}_{5}, \mathrm{X}=\mathrm{H} ; \mathrm{R} \mathrm{10/141-I;R}$, $\mathbf{R}^{1}=\mathrm{CH}_{3}, \mathbf{R}^{2}=\mathrm{C}_{2} \mathrm{H}_{5}, \mathrm{X}=\mathrm{C}_{6} \mathrm{H}_{5} . \mathrm{CH}_{2} ; \mathbf{R} 10 / 122-\mathrm{I} ; \mathbf{R}, \mathbf{R}^{1}=\mathrm{CH}_{3}, \mathbf{R}^{2}=n \mathrm{C}_{3} \mathrm{H}_{7}$, $\mathbf{X}=\mathbf{H} ; \mathbf{R} 10 / 158-\mathrm{I} ; \mathbf{R}, \mathbf{R}^{1}=\mathbf{C H}_{3}, \mathbf{R}^{2}=n \mathrm{C}_{3} \mathrm{H}_{7}, \mathbf{X}=\mathrm{Cl} ; \mathbf{R} 10 / 154-\mathrm{I} ; \mathbf{R}, \mathbf{R}^{1}=\mathbf{C H}_{3}$ $\mathrm{R}^{2}={ }_{n} \mathrm{C}_{3} \mathrm{H}_{7}, \mathrm{X}=\mathrm{Br} ; \mathrm{R} \mathrm{10} / 163-\mathrm{I} ; \mathrm{R}, \mathrm{R}^{1}=\mathrm{CH}_{3}, \mathrm{R}^{2}=n \mathrm{C}_{3} \mathrm{H}_{7}, \mathrm{X}=\mathrm{I} ; \mathrm{R} \mathrm{10} / 162-\mathrm{I}$; $\mathbf{R}, \mathbf{R}^{1}=\mathrm{CH}_{3}, \mathbf{R}^{2}=n \mathrm{C}_{3} \mathrm{H}_{7}, \mathbf{X}=\mathrm{C}_{6} \mathrm{H}_{5} . \mathrm{CH}_{2}$. 
R 10/129-II; R, $\mathrm{R}^{1}=\mathrm{CH}_{3}, \mathrm{R}^{2}=\mathrm{CH}_{3}, \mathrm{X}=\mathrm{H} ; \mathrm{R} \mathrm{10/98-II} ; \mathrm{R}, \mathrm{R}^{1}=\mathrm{CH}_{3}$, $\mathbf{R}^{2}=\mathrm{C}_{2} \mathrm{H}_{5}, \mathbf{X}=\mathrm{H} ; \mathrm{R} 10 / 153-\mathrm{II} ; \mathrm{R}, \mathbf{R}^{1}=\mathrm{CH}_{3}, \mathbf{R}^{2}=n \mathrm{C}_{3} \mathrm{H}_{7}, \mathrm{X}=\mathrm{H} ; \mathrm{R} \mathrm{10} /$ 152-II; $\mathbf{R}, \mathbf{R}^{1}=\mathrm{CH}_{3}, \mathbf{R}^{2}=n \mathrm{C}_{4} \mathrm{H}_{9}, \mathrm{X}=\mathrm{H}$.

Further investigations with lower concentrations of the same analogues showed that the $2^{\prime}$-ethoxy (R 10/32), the $2^{\prime}$-n-propoxy (R 10/122) and the 2 '-n-propylthioether ( $R$ 10/153) analogues of griseofulvin were probably the most active compounds against apple scab, all being superior to the corresponding analogues substituted by halogen or benzyl at the $3^{\prime}$-position.

Griseofulvin is known to be particularly effective against some powdery mildews; as this activity appears to be largely dependent upon systemic action (Rhodes, Crosse, McWilliam, Tootill \& Dunn, 1957), we began an investigation into the effectiveness against powdery mildews of the three compounds which had proved to be most effective in the tests against apple scab. All three compounds showed greatly enhanced activity over that of griseofulvin against Erysiphe graminis on barley, only $5 \mu \mathrm{g} . / \mathrm{ml}$. of each analogue being required for the LD 95 dose as compared with more than $100 \mu \mathrm{g}$. $/ \mathrm{ml}$. for griseofulvin.

Table 4. Control of chrysanthemum mildew (Oidium chrysanthemi) by 2'-propoxygriseofulvin $(\boldsymbol{R} 10 / 122)$ applied as foliage spray at intervals of 14 days from midOctober

\begin{tabular}{|c|c|c|c|c|c|c|}
\hline \multirow{4}{*}{$\begin{array}{c}\text { Date of } \\
\text { disease } \\
\text { estimation }\end{array}$} & \multicolumn{6}{|c|}{ Percentage reduction of chrysanthemum mildew } \\
\hline & \multicolumn{3}{|c|}{ var. 'Sterling' } & \multicolumn{3}{|c|}{ var. 'Mayford Perfection' } \\
\hline & \multicolumn{2}{|c|}{$\begin{array}{c}\text { 2'-Propoxy-griseofulvin } \\
(\mu \mathrm{g} \cdot / \mathrm{ml} .)\end{array}$} & \multirow{2}{*}{$\begin{array}{c}\text { Karathane } \\
(\mu \mathrm{g} \cdot / \mathrm{ml} .) \\
\mathbf{1 0 0}\end{array}$} & \multicolumn{2}{|c|}{$\begin{array}{c}2^{\prime} \text {-Propoxy-griseofulvin } \\
(\mu \mathrm{g} . / \mathrm{ml} .)\end{array}$} & \multirow{2}{*}{$\begin{array}{c}\text { Karathane } \\
(\mu \mathrm{g} \cdot / \mathrm{ml} .) \\
100\end{array}$} \\
\hline & 100 & 25 & & 100 & $\mathbf{2 5}$ & \\
\hline 15-11-60 & 61 & 60 & 66 & 26 & $\mathbf{5 7}$ & 57 \\
\hline 28-11-60 & 100 & 98 & 100 & 46 & $\mathbf{5 4}$ & 61 \\
\hline 19-12-60 & 98 & 99 & 99 & 75 & 80 & 81 \\
\hline $4-1-61$ & 100 & 100 & 100 & 85 & 83 & 86 \\
\hline
\end{tabular}

Further tests showed that the $2^{\prime}$-propoxy analogue of griseofulvin (R 10/122) was about equal in activity to Dinocap (used as the approximately $25 \%$ wettable powder marketed by Rohm and Haas Company under the trade mark 'Karathane') in greenhouse protection tests against powdery mildew of cucumber (Erysiphe cichoracearum), both materials giving almost complete control at $80 \mu \mathrm{g} . / \mathrm{ml}$. The dose-response curve of the griseofulvin analogue was, however, much steeper than that of Dinocap, with the result that the analogue compared progressively less favourably as the concentration was diminished. The $2^{\prime}$-propoxy analogue of griseofulvin ( $\mathrm{R}$ 10/122) proved to be highly effective as a foliage protectant spray against chrysanthemum mildew (Oidium chrysanthemi), 25 and $100 \mu \mathrm{g} . / \mathrm{ml}$. applied every 14 days giving virtually complete protection in greenhouse tests (Table 4). This analogue was much less effective against apple mildew (Podosphaera leucotricha), $160 \mu \mathrm{g} . / \mathrm{ml}$. giving only partial protection. 


\section{DISCUSSION}

Rhodes (1962), in a critical review of the status of griseofulvin in crop protection, noted that three distinct processes contribute to the antifungal action of griseofulvin in plants: the effect of griseofulvin on the pathogen; the transportation of the antibiotic within the host; the extent to which chemical degradation occurs in both host and pathogen. These considerations may help to explain some of the results now reported.

In general, analogues which exhibited enhanced activity in vitro against plant pathogenic fungi also showed to advantage in greenhouse tests. Maximum in vitro activity in the homologous series of alkyloxy replacements at the $2^{\prime}$-position is shown by the $2^{\prime}$-propoxy (R 10/122) and $2^{\prime}$-butoxy (S 2) analogues of griseofulvin; this accords with the relative order of activity in this series of compounds against Botrytis allii reported by Crowdy, Grove \& McCloskey (1959) and with their suggestion that effects on physical properties may be dominant.

Hyphal walls of the numerous test fungi may be expected to show some diversity in their requirements for the physical properties of an analogue that is to give optimum adsorption by, and penetration of, the hyphae. Restriction of improved activity in vitro to a limited number of diverse test organisms may then simply reflect the extent to which these optimum requirements depart from the mean of those against all the test organisms. The small number of analogues which showed improved performance against the dermatophytes may be due to the relative homogeneity of this group and close approximation of their optimum requirements to the physical properties of the $2^{\prime}$-ethoxy-3'-benzyl ( $R$ 10/141) analogue of griseofulvin, to which they are highly susceptible.

The most active of the $2^{\prime}$-alkyloxy analogues of griseofulvin performed relatively better in vivo but the most active of the $2^{\prime}$-alkyloxy-3' halogen-substituted analogues of griseofulvin were relatively inferior to expectation in plants, particularly in tests where local systemic action offered a premium. These observations suggest that substitution at the $3^{\prime}$-position, although enhancing in vitro antifungal activity, may interfere with processes that affect local systemic action in plants; for example penetration into the leaf or translocation within it. Similarly, optimum requirements for adsorption by hyphae and penetration into dermatophytic fungi must differ from those needed for entry to dermal tissue of the animal host, because Neves (1962) and Munro-Ashman (1962) reported that topical application of the $2^{\prime}$-ethoxy$3^{\prime}$-benzyl (R 10/141) analogue of griseofulvin which showed enhanced activity in vitro against dermatophytic fungi did not control tinea pedis in man.

These observations on the antifungal activity in vivo and in vitro of the ring $\mathrm{C}$ analogues of griseofulvin accord with the suggestion of Crowdy et al. (1959) that for each similar group of griseofulvin analogues there may be an optimum high oil/water partition coefficient, both for increased activity in vitro and for systemic antifungal activity. It is notable that Crowdy et al. (1959) found the 2 '-propoxy analogue of griseofulvin to be non-systemic when tested by root application to tomato plants; in our tests this analogue showed local systemic action and gave good protection when applied as a foliage spray, especially in the test against apple scab where local systemic action was probably at a premium. This suggests a greater divergence between the partition coefficient which gives optimum in vitro activity 
and that needed for good translocation from roots to shoots, than between the partition coefficients which afford optimum in vitro and local systemic action in foliage, respectively.

Physical properties alone can hardly account for the enormous and specific increase in activity observed in the hyphal curling test when halogen or benzyl groups were substituted in the $3^{\prime}$-position. Optimum activity in the $2^{\prime}$-n -propoxy analogues of griseofulvin was found with $I\left(R\right.$ 10/163) or $\mathrm{C}_{6} \mathrm{H}_{5}, \mathrm{CH}_{2}(\mathrm{R} \mathrm{10/162)}$ in the $3^{\prime}$-position, but in the $2^{\prime}-n$-butoxy analogues of griseofulvin peak activity occurred with bromine substitution in the $\mathbf{3}^{\prime}$-position. It is notable that Botrytis allii can demethylate griseofulvin at the $2^{\prime}$-position to griseofulvic acid (Boothroyd, Napier \& Somerfield, 1961); perhaps the specific and substantial enhancement of activity observed against this organism is due to supplementary effects of the $\mathbf{3}^{\prime}$ substituent group on electron distribution within the $\beta$-diketone-enol-ether system, diminishing the tendency to de-alkylation of the 2 '-position.

The specificity of some of the responses observed suggests that in any antifungal screening it is important where possible to select as test fungi those organisms that are the objectives for control in the field; the selection of fungi for tests because of convenience in the laboratory may result in misleading conclusions. Similarly, correlation of chemical structure with antifungal activity may have little meaning unless the responses of a wide range of fungi are examined.

The $2^{\prime}$-propoxy analogue of griseofulvin, despite its failure to give systemic control of Alternaria solani when watered to roots of tomato plants (Crowdy et al. 1959), seems to be the best antifungal substance among the $\mathbf{3 0 0}$ or more analogues tested for potential use as plant protectants; in our tests it showed improved activity in vitro and in vivo, exhibited local systemic action as a foliage spray, gave a good performance against apple scab (Venturia inaequalis) and provided excellent control of chrysanthemum mildew (Oidium chrysanthemi) in greenhouse tests. The activity of the 2 '-propoxy analogue of griseofulvin ( $R$ 10/122) against apple scab was, however, much inferior to that of the antibiotic venturicidin (Rhodes et al. 1961), and it should be noted that complete control of chrysanthemum mildew has already been obtained by root-watering with griseofulvin itself (Rhodes, 1962). Having regard to the increased cost relative to griseofulvin, the outlook for practical use of analogue $R$ 10/122 must be considered to be unfavourable.

\section{REFERENCES}

Arkley, V., AtTenburrow, J., Gregory, G. I. \& Walker, T. (1963). Griseofulvin analogues. I. Modification of the aromatic ring. J. chem. Soc. p. 1260.

Arkley, V., Gregory, G. I. \& Walker, T. (1963). Griseofulvin analogues. VI. Dichlorogriseofulvin and some of its derivatives. J. chem. Soc. p. 1603.

BARneTt, S. M. (1960). Treatment of various fungal diseases with griseofulvin discussed. Wis. med. J. 59, 421.

Boothroyd, B., Napier, E. J. \& Somenfield, G. A. (1961). The demethylation of griseofulvin by fungi. Biochem. J. 80, 34 .

Brian, P. W., Curtis, P. J. \& Hemming, H. G. (1946). A substance causing abnormal development of fungal hyphae produced by Penicillium janczeroskii Zal. I. Biological assay, production and isolation of curling factor. Trans. Brit. mycol. Soc. 29, 173.

Crosse, R., McWilliam, R., Rhodes, A. \& Dunn, A. T. (1960). Antifungal action of streptomycin-copper chelate against Phytophthora infestans on tomato (Lycopersicon esculentum). Ann. appl. Biol. 48, 270. 
Growdy, S. H., Grove, J. F. \& McCloskey, P. (1959). The translocation of antibiotics in higher plants. 4. Systemic antifungal activity and chemical structure in griseofulvin relatives. Biochem. J. 72, 241.

Goodall, S. R., Gregory, G. I. \& Walker, T. (1963). Griseofulvin analogues. VII. Replacement in the aromatic ring. J. chem. Soc. p. 1610.

Gregory, G. I., Holton, P. J., Robinson, H. \& Walker, T. (1962). Griseofulvin analogues. II. Some $3^{\prime}$ alkyl griseofulvic acids and their enol esters. J. chem. Soc. p. 1269.

Grutter, F. H., Gaughran, E. R. L., Swartz, H. E. \& Kamp, L. F. (1959). Microbiological assay of griseofulvin using Neurospora crassa. Bact. Proc. A 46.

KIRKhaM, D. S. (1956). A culture technique for Venturia spp. and a turbidimetric method for the estimation of comparative sporulation. Nature, Lond. 178, 550.

Munro-Ashman, D. (1962). Topical griseofulvin analogue in tinea pedis. Trans. St John's Hosp. derm. Soc., Lond. 48, 108.

Neves, H. (1962). Tinea pedis-topical treatment with griseofulvin and an analogue. Trans. St John's Hosp. derm. Soc., Lond. 48, 103.

Page, J. E. \& Staniforth, S. E. (1962). Griseofulvin analogues. V. Infrared absorption. J. chem. Soc. p. 1292.

Page, J. E. \& Staniforth, S. E. (1963). Griseofulvin analogues. VIII. Infrared absorption of griseofulvic acid and related compounds. J. chem. Soc. p. 1814.

RHODEs, A. (1962). Status of griseofulvin in crop protection. In Antibiotics in agriculture. Proceedings of the University of Nottingham Ninth Easter School in Agricultural Science, p. 101. London: Butterworth's Scientific Publications.

Rhodes, A., Crosse, R., McWilliam, R., Tootill, J. P. R. \& Dunn, A. T. (1957). Small-plot trails of griseofulvin as a fungicide. Ann. appl. Biol. 45, 215.

Rhodes, A., Fantes, K. H., Boothroyd, B., McGonagle, M. P. \& Crosse, R. (1961). Venturicidin: a new antifungal antibiotic of potential use in agriculture. Nature, Lond. $192,952$.

Stephenson, L., Walker, T., Warburton, W. K. \& WebB, G. B. (1962). Griseofulvin analogues. IV. The preparation and properties of some chlorides. J. chem. Soc. p. 1282.

Sternberg, T. H. (1960). A brief review of the value of griseofulvin as a therapeutant. Curr. Ther. $2,158$.

Uvarov, O. (1961). Recent advances in the treatment of skin diseases with special reference to griseofulvin. Vet. Rec. 73, 258.

Walker, T., Warburton, W. K. \& WebB, G. B. (1962). Griseofulvin analogues. III. Halogen derivatives of griseofulvin. J. chem. Soc. p. 1277.

Williams, D. I. (1960). The pharmacology, toxicology and clinical uses of griseofulvin are reviewed. Practitioner, 184, 383. 